\title{
MORPHOLOGICAL AND PHYSIOLOGICAL TRAITS IN SEEDLINGS' POPULATIONS OBTAINED FROM THE HYBRIDIZATION OF PROMISING GENOTYPES OF QUINCE (CYDONIA OBLONGA MILL.)
}

\author{
Short communication \\ Maryam TATARI ${ }^{1 *}$, Azam JAFARI $^{2}$, Hojat NAJAFI SOLARI ${ }^{2}$ \\ ${ }^{1}$ Horticulture Crops Research Department, Isfahan Agricultural and Natural \\ Resources Research and Education Center, AREEO, Isfahan, Iran \\ ${ }^{2}$ Department of Horticultural Science, Ardakan University, Ardakan, Iran
}

Received: December 2019; Accepted: September 2020

\begin{abstract}
Some morphological and physiological traits of seedlings in eight quince populations from seeds obtained in 2015 (350 progenies per population) were evaluated in 2017 and 2018. They resulted from open pollination of 'Viduja', KVD2 and KVD4 genotypes as well as from the crossings of 'Viduja' $\times$ KVD4, KVD2 $\times$ 'Viduja', KVD2 $\times$ KVD4, KVD4 $\times$ 'Viduja' and KVD4 $\times$ KVD2. Populations showed significant differences in some measured traits, including height and diameter of seedlings, canopy width, annual growth, leaf iron, and chlorophyll content, as well as catalase and peroxidase activities. Based on the results of descriptive statistics, a high variation coefficient was observed in canopy width, peroxidase activity, chlorophyll, and iron content traits. Results of simple correlation showed that there were significant positive correlations between leaf iron content and catalase activity as well as canopy width with both annual growth and leaf length. Cluster analysis among populations based on total traits divided the populations into four distinct groups. The role of the female parents was visible in reciprocal crosses of 'Viduja' $\times$ KVD4 and KVD2 $\times$ KVD4, but all populations with similar female parents were not grouped in the same clusters.
\end{abstract}

Keywords: hybridization, diversity, population, quince

\section{INTRODUCTION}

Quince (Cydonia oblonga Mill.) is a domestic species of southwestern Europe and Asia Minor (Rodríguez-Guisado et al. 2009). Iran is one of the most important producers of quince in the world. The growing of a single-cultivar in the quince orchard is common, but there are some economic concerns in a single-cultivar orchard, such as pollination and fruit set problems, as well as decreasing quality and yield (Tatari et al. 2018).
In single-cultivar quince orchards dominates selfpollination, resulting in flower and fruitlet abscission, which leads to the severe decline of yields (Tatari et al. 2018). The cultivation of several cultivars in the quince orchards can prevent abscission and increase yield. Until then, no purposeful hybridization between promising genotypes were carried out in Iran. In this study, the results of evaluation of quince hybrids at the vegetative phase are presented, with the aim of searching for useful correlations among them. 


\section{MATERIALS AND METHODS}

\section{Plant materials}

Eight populations of quince, the seeds of which were harvested in 2015, were assessed in 2017 and 2018 at Isfahan Agricultural and Natural Resources Research Center, Iran. The first three populations resulted from open pollinations of 'Viduja' and KVD2 and KVD4 genotypes. The remaining populations were the results of the following crosses: 'Viduja' $\times$ KVD4, KVD2×'Viduja', KVD2 $\times$ KVD4, KVD4 $\times$ 'Viduja' and KVD4 $\times$ KVD2. Parent characteristics are listed in Table 1 (Tatari et al. 2018).

Hybrid seeds of each crossing combination and seeds of open pollination were sown in separate rows in the soil with a sandy loam texture at five centimeter intervals in December to satisfy the chilling requirement. 350 seedlings per population were transferred from the nursery to the main field and planted at intervals of $2 \times 2$ meters in March 2016. Soil pH was 7.75. Each treatment (population) was represented by 7 replications and 50 seedlings per replication. Irrigation and orchard management were carried out regularly.

\section{Measurement of traits}

Some growth characteristics, including seedling height and stem diameter, canopy width, leaf dimensions, annual growth increase, annual shoot diameter, leaf iron and chlorophyll content as well as catalase and peroxidase activities were measured.
Seedling diameter was measured at a height of $5 \mathrm{~cm}$ from the soil surface. The measurement methods, abbreviations and units of traits are given in Table 2 . These traits were evaluated for all seedlings.

Leaf samples for analysis were collected in the July 2017 and 2018. The concentration of iron in leaf extract was measured using atomic absorption spectrometry model Shimadzu AA-670, Kyoto, Japan (Walinga 1989). To obtain a total chlorophyll content, the absorbance of the extracts was measured using a spectrophotometer (T80 Double Beam UV/Visible) at 645 and $663 \mathrm{~nm}$. Chlorophyll content was calculated using Arnon's (1949) equations (Hiscox \& Israelstam 1979). For guaiacol peroxidase, the oxidation of guaiacol was measured by the increase in absorbance at $470 \mathrm{~nm}$ for $1 \mathrm{~min}$, using spectrometry, as given above (Zhang 1992). Activity of catalase was obtained using the method of Aebi (1984), where the decomposition of $\mathrm{H}_{2} \mathrm{O}_{2}$ was measured by the decline in absorbance at $240 \mathrm{~nm}$ for the $70 \mathrm{~s}$, using spectrometry, as given above.

\section{Data analysis}

This research was conducted as a randomized complete block design. Analysis of variance among populations was carried out on average results from two years by SAS software (version 9.1) and the means were compared by the LSD method. Descriptive statistics, the simple correlation between traits (using the Pearson method) and cluster analysis (Ward method based on squared Euclidean distance) were carried out using SPSS (version 15).

Table 1. Characteristics of parents used for creating new quince populations

\begin{tabular}{|c|c|}
\hline Parents & Characteristics \\
\hline $\begin{array}{l}\text { 'Viduja' } \\
\text { (KVD1) }\end{array}$ & $\begin{array}{l}\text { Early flowering, high yield, fruit production on short branches (spore), dwarf, small } \\
\text { to medium fruit, sweet and low astringency fruit, favorable edible quality, relative toler- } \\
\text { ance to fire blight }\end{array}$ \\
\hline KVD2 & $\begin{array}{l}\text { Early flowering, high yield, fruit production on short branches (spore), medium to large } \\
\text { fruit, relatively good edible quality, longer storage period than 'Viduja', more canopy } \\
\text { width and tree height than others }\end{array}$ \\
\hline KVD4 & $\begin{array}{l}\text { Early flowering, high yield, fruit production on short branches (spore), dwarf, medium } \\
\text { to large fruit, sour fruit, high leaf phenol content, higher catalase, and peroxidase activity, } \\
\text { chlorophyll content in leaves as well as longer storage period than others }\end{array}$ \\
\hline
\end{tabular}


Table 2. Evaluated characteristics of seedlings, units, abbreviations, and methods of evaluation

\begin{tabular}{|c|c|c|c|c|}
\hline Trait & Units & Abbreviation & $\begin{array}{c}\text { Measurement } \\
\text { method }\end{array}$ & $\begin{array}{c}\text { Time } \\
\text { of measurement }\end{array}$ \\
\hline Leaf length & $\mathrm{cm}$ & LL & Ruler & July \\
\hline Leaf width & $\mathrm{cm}$ & LW & Ruler & July \\
\hline Chlorophyll content & $\mathrm{mg} \cdot \mathrm{g}^{-1} \mathrm{FW}$ & ChlC & Protocol & July \\
\hline Chlorophyll Index & - & ChlI & SPAD & July \\
\hline Leaf iron content & $\mathrm{mg} \cdot \mathrm{kg}^{-1}$ & $\mathrm{FeC}$ & Protocol & July \\
\hline Catalase Activity & $\mathrm{nmol} \cdot \mathrm{min}^{-1} \cdot \mathrm{g} \mathrm{FW}^{-1}$ & CAT & Protocol & July \\
\hline Peroxidase Activity & $\mathrm{nmol} \cdot \mathrm{min}^{-1} \cdot \mathrm{g} \mathrm{FW}^{-1}$ & POD & Protocol & July \\
\hline Seedling height & $\mathrm{cm}$ & $\mathrm{SH}$ & Meter & after leaf abscission \\
\hline Seedling diameter & $\mathrm{mm}$ & SD & Caliper & after leaf abscission \\
\hline Canopy width & $\mathrm{cm}$ & $\mathrm{CW}$ & Meter & after leaf abscission \\
\hline Annual growth & $\mathrm{cm}$ & $\mathrm{AG}$ & Ruler & after leaf abscission \\
\hline Annual shoot diameter & $\mathrm{mm}$ & ASD & Caliper & after leaf abscission \\
\hline Angle of the primary shoots & degree & APS & protractor & after leaf abscission \\
\hline Internode length & $\mathrm{cm}$ & IL & Ruler & after leaf abscission \\
\hline
\end{tabular}

\section{RESULTS AND DISCUSSION}

The highest coefficient of variation was obtained for peroxidase activity and the lowest for leaf length (Table 3). The high coefficient of variation indicates the high diversity in the trait among seedlings from the same crossing. Traits with a high variation coefficient provide a greater chance of passing that trait to offspring. Plant peroxidases are important as they catalyze the reduction of hydrogen peroxide and scavenge reactive oxygen species (Wu et al. 1999). Also, leaf chlorophyll content showed a high coefficient of variation of $23.9 \%$. High variation in peroxidase activity and leaf chlorophyll content were reported by Petrokas and Stanys (2008) and Mohammadi et al. (2014), respectively. Among the morphological traits, canopy width $(23.1 \%)$ and leaf length $(5.8 \%)$ had the highest and the lowest coefficient of variation, respectively (Table 3 ).
Only KVD2 (the highest $-60 \mathrm{~cm}$ ) and KVD4 $\times$ 'Viduja' (the lowest $-39.6 \mathrm{~cm}$ ) seedlings differed significantly in height. All other populations were intermediate (Table 4). The biggest seedling diameter was found in populations from 'Viduja' $(10.8 \mathrm{~cm})$ and KVD4 $(11.1 \mathrm{~cm})$ open pollinations and the lowest in populations from KVD2 $\times$ KVD4 and KVD4 $\times$ 'Viduja' crosses $(8.9$ and $8.9 \mathrm{~cm})$. Seedlings in population KVD4 $\times$ 'Viduja' were the lowest with the height and diameter. Both parents of this population were lower than KVD2 genotype and thus their progeny produced lower and thinner shoots.

The biggest annual growth was scored in KVD2 $\times$ 'Viduja' $(9.5 \mathrm{~cm})$ and least in 'Viduja' $(5.9 \mathrm{~cm})$. Similar dependencies were between these two populations concerning canopy with the exception that the smallest value of this trait was in KVD4 and in KVD2 open populations. 
Table 3. Descriptive statistics for values of assessed features in the quince populations (averages for 2017-2018)

\begin{tabular}{lccccc}
\hline Characteristics & Minimum & Maximum & Mean & Standard deviation & Coefficient variation (\%) \\
\hline Leaf length & 3.4 & 4.1 & 3.8 & 0.2 & 5.8 \\
Leaf width & 2.4 & 3.8 & 3 & 0.4 & 13.5 \\
Chlorophyll content & 2 & 3.9 & 2.9 & 0.7 & 23.9 \\
Chlorophyll Index & 49.9 & 78.6 & 56.7 & 9.2 & 16.1 \\
Leaf iron content & 112 & 224 & 178.4 & 32.5 & 18.2 \\
Catalase Activity & 0.001 & 0.01 & 0.009 & 0.0009 & 9.3 \\
Peroxidase Activity & 0.02 & 0.07 & 0.04 & 0.02 & 42.5 \\
Seedling height & 39.6 & 60.04 & 49.4 & 5.9 & 12.0 \\
Seedling diameter & 8.8 & 11.06 & 10.2 & 0.8 & 8.3 \\
Canopy width & 22 & 52.8 & 39.7 & 9.2 & 23.1 \\
Annual growth & 5.9 & 9.5 & 7.6 & 1.1 & 15.0 \\
Annual shoot diameter & 6.5 & 9.3 & 7.6 & 0.9 & 11.9 \\
Angle of the primary shoots & 41 & 55.5 & 51.5 & 4.7 & 8.09 \\
Internode length & 1.4 & 1.8 & 1.6 & 0.1 & 8.03 \\
\hline
\end{tabular}

Table 4. Values of assessed features in the quince populations (averages for 2017-2018)

\begin{tabular}{ccccccccc}
\hline Population & ChlC & FeC & CAT & POD & SH & SD & CW & AG \\
\hline 1 & $3.06 \mathrm{~b}$ & $167 \mathrm{c}$ & $9.2 \mathrm{~b}$ & $17.9 \mathrm{~d}$ & $48.7 \mathrm{ab}$ & $10.8 \mathrm{a}$ & $37.8 \mathrm{~b}$ & $5.9 \mathrm{c}$ \\
2 & $2 \mathrm{c}$ & $171 \mathrm{c}$ & $10 \mathrm{a}$ & $35.7 \mathrm{c}$ & $60.04 \mathrm{a}$ & $10.5 \mathrm{ab}$ & $45.5 \mathrm{ab}$ & $8.4 \mathrm{ab}$ \\
3 & $2.3 \mathrm{c}$ & $224 \mathrm{a}$ & $10.2 \mathrm{a}$ & $64.5 \mathrm{a}$ & $45.6 \mathrm{ab}$ & $11.06 \mathrm{a}$ & $39.2 \mathrm{~b}$ & $7.5 \mathrm{abc}$ \\
4 & $3.04 \mathrm{~b}$ & $201 \mathrm{ab}$ & $7.5 \mathrm{c}$ & $25.1 \mathrm{~d}$ & $49.5 \mathrm{ab}$ & $10.3 \mathrm{ab}$ & $39.3 \mathrm{~b}$ & $7.4 \mathrm{abc}$ \\
5 & $3.9 \mathrm{a}$ & $112 \mathrm{~d}$ & $10.2 \mathrm{a}$ & $40.5 \mathrm{c}$ & $51.9 \mathrm{ab}$ & $10.7 \mathrm{a}$ & $52.8 \mathrm{a}$ & $9.5 \mathrm{a}$ \\
6 & $2.2 \mathrm{c}$ & $178.5 \mathrm{bc}$ & $10.2 \mathrm{a}$ & $53.6 \mathrm{~b}$ & $52.8 \mathrm{ab}$ & $8.9 \mathrm{~b}$ & $46.5 \mathrm{ab}$ & $8.4 \mathrm{ab}$ \\
7 & $3.7 \mathrm{ab}$ & $181 \mathrm{bc}$ & $10 \mathrm{a}$ & $69.3 \mathrm{a}$ & $39.6 \mathrm{~b}$ & $8.8 \mathrm{~b}$ & $34.8 \mathrm{~b}$ & $7.09 \mathrm{abc}$ \\
8 & $3.3 \mathrm{ab}$ & $193 \mathrm{bc}$ & $10.2 \mathrm{a}$ & $70.7 \mathrm{a}$ & $45.6 \mathrm{ab}$ & $10.4 \mathrm{ab}$ & $22 \mathrm{c}$ & $6.6 \mathrm{bc}$ \\
\hline
\end{tabular}

$\begin{array}{ll}\text { Population 1: 'Viduja' open pollination } & \text { Population 5: KVD2 } \times \text { 'Viduja' } \\ \text { Population 2: KVD2 open pollination } & \text { Population 6: KVD2 } \times \text { KVD4 } \\ \text { Population 3: KVD4 open pollination } & \text { Population 7: KVD4 } \times \text { 'Viduja' } \\ \text { Population 4: 'Viduja' (female) } \times \text { KVD4 (male) } & \text { Population 8: KVD4 } \times \text { KVD2 }\end{array}$

Similar letters in each column indicate no significant difference at the 5\% level of LSD test 
Chlorophyll and Fe contents were negatively correlated (Table 5). The highest Fe content was found in KVD4 open pollinations and significantly lowest in KVD2 $\times$ 'Viduja', 'Viduja' open and KVD2 open populations (Table 4). The highest content of chlorophyll was measured in KVD2 $\times$ 'Viduja' and significantly lowest in KVD2 $\times$ 'Viduja' and significantly lowest in KVD2 open and KVD2 $\times$ KVD4.

The range of studied traits is shown in Table 3 . The range of iron content in the studied populations was from 112 to $224 \mathrm{mg} \cdot \mathrm{kg}^{-1}$ (the studied seedlings were not fed with iron or micro-elements). The range of Fe contents in the study of Abdollahi and Ahmadi (2017) on different quince genotypes were from 75 to $135 \mathrm{mg} \cdot \mathrm{kg}^{-1}$ fresh weight. The range of leaf chlorophyll content was also high - between 1.9 and $3.9 \mathrm{mg} \cdot \mathrm{g}^{-1}$ of fresh weight. Similar range was reported by Rajabpoor et al. (2014) for wild almond species (1.5 to $3.7 \mathrm{mg} \cdot \mathrm{g}^{-1}$ fresh weight). Iron plays an essential role in chlorophyll biosynthesis and the concentration of active iron is directly correlated with chlorophyll content (Sahin et al. 2017), but in the present study, population KVD2 $\times$ 'Viduja' showed the highest total chlorophyll and the lowest total iron contents. The total iron content in the leaves is not always a reliable parameter for indicating the chlorophyll content, iron availability, and chlorosis. There are reports that iron is stabilized in the apoplastic space of the cell and is not transmitted to the cytoplasm and organelles. Under these conditions, the leaves may show symptoms of chlorosis, which is called the Iron chlorosis paradox (Sahin et al. 2017), so the active iron has a greater role in determining the actual content of available iron of leaves (Samar et al. 2010).

The level of CAT activity was stable within populations and was about $10 \mathrm{nmol} \cdot \mathrm{min}^{-1} \cdot \mathrm{g} \mathrm{FW}^{-1}$. Only two populations had lower value of this trait 'Viduja' $\times$ KVD4 (7.5) and 'Viduja' open (9.2) (Table 4). Both populations had 'Viduja' as mother.
Enzymes such as peroxidase, which appear in different isoforms in the cell, scavenge reactive oxygen species. The activity of this enzyme continues throughout the life of plants from germination to the aging stages participating in the control of cellular elongation, defense mechanisms and several other functions (Wu et al. 1999). In three populations, where KVD4 was in maternal position had the highest peroxidase activity (70.7 to $64.5 \mathrm{nmol} \cdot \mathrm{min}^{-1} \cdot \mathrm{g} \mathrm{FW}^{-1}$ ). The lowest POD value was in populations where 'Viduja' was in the maternal position (17.9 and $25.1 \mathrm{nmol} \cdot \mathrm{min}^{-1} \cdot \mathrm{g} \mathrm{FW}^{-1}$ ).

Correlation of traits is used to investigate a logical and meaningful relationship between traits (Table 5). According to the results, the correlation among most traits was not significant and only some traits showed high correlations. Seedling height was positively and significantly correlated with chlorophyll index, canopy width with annual growth and leaf length, and the total iron content in leaves showed a significant positive correlation with catalase activity. Catalase is one of the most important hydrogen peroxide neutralizing enzymes in plants. This enzyme contains iron as a cofactor in its structure and its activity is reduced under iron deficiency. Correlations between this enzyme activity and leaf iron content have also been reported previously (Sun et al. 2007). For some species, a positive linear relationship between the chlorophyll index and total extractable leaf chlorophyll has been determined (Marquard \& Tipton 1987), but this relationship was not confirmed in the present study.

The studied populations were classified into four distinct groups at 10 squared Euclidean distance based on the Ward method (Fig. 1). 'Viduja' open pollination, 'Viduja' $\times$ KVD4, KVD2 $\times$ 'Viduja' and KVD2 $\times$ KVD4 populations that one of their parents was 'Viduja' or KVD2, were placed in the same group. The same levels of seedling height, seedling diameter, and chlorophyll index, as well as lower total iron content, were characteristic for this group. 
Table 5. Correlation for values of assessed features in the quince populations (averages for 2017-2018)

\begin{tabular}{|c|c|c|c|c|c|c|c|c|c|c|c|c|c|c|}
\hline & ChlI & SH & SD & $\mathrm{CW}$ & AG & ASD & LL & LW & APS & IL & $\mathrm{FeC}$ & CAT & POD & ChlC \\
\hline ChlI & 1 & & & & & & & & & & & & & \\
\hline $\mathrm{SH}$ & $0.769 *$ & 1 & & & & & & & & & & & & \\
\hline SD & 0.019 & 0.669 & 1 & & & & & & & & & & & \\
\hline $\mathrm{CW}$ & 0.095 & 0.383 & 0.675 & 1 & & & & & & & & & & \\
\hline AG & -0.619 & -0.385 & -0.054 & $0.786^{*}$ & 1 & & & & & & & & & \\
\hline ASD & -0.401 & -0.180 & 0.262 & 0.691 & 0.616 & 1 & & & & & & & & \\
\hline LL & 0.256 & 0.241 & 0.208 & $0.765^{*}$ & -0.211 & 0.451 & 1 & & & & & & & \\
\hline LW & 0.298 & -0.127 & -0.634 & -0.482 & 0.133 & -0.405 & -0.069 & 1 & & & & & & \\
\hline APS & 0.242 & -0.183 & -0.213 & 0.174 & -0.180 & 0.169 & 0.495 & 0.183 & 1 & & & & & \\
\hline IL & 0.11 & 0.318 & 0.356 & 0.485 & 0.440 & 0.283 & 0.313 & 0.356 & -0.024 & 1 & & & & \\
\hline $\mathrm{FeC}$ & -0.172 & 0.182 & -0.008 & -0.374 & -0.386 & -0.469 & -0.158 & -0.153 & -0.430 & -0.493 & 1 & & & \\
\hline CAT & 0.112 & 0.168 & -0.307 & -0.555 & -0.482 & -0.628 & -0.132 & 0.192 & -0.179 & -0.513 & $0.895 * *$ & 1 & & \\
\hline POD & -0.184 & -0.293 & -0.606 & -0.306 & 0.415 & 0.126 & 0.128 & 0.622 & 0.225 & 0.085 & 0.131 & 0.357 & 1 & \\
\hline ChlC & -0.585 & -0.768 & -0.378 & 0.068 & 0.249 & 0.538 & 0.146 & -0.355 & 0.135 & -0.454 & -0.056 & -0.160 & 0.162 & 1 \\
\hline
\end{tabular}

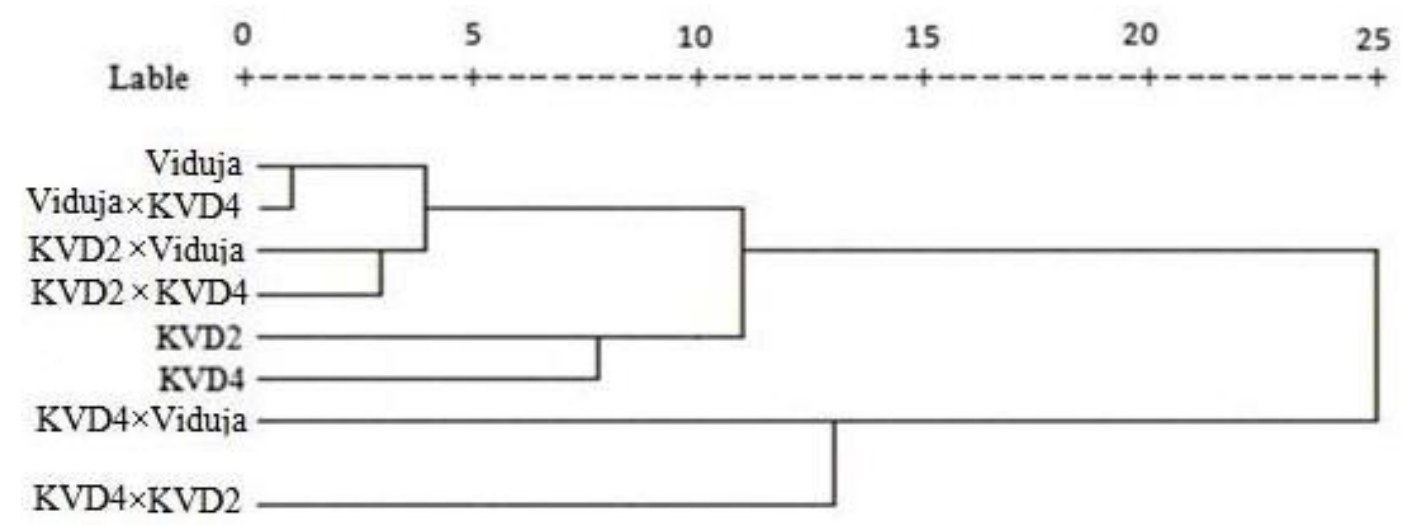

Figure 1. Grouping of studied quince populations based on the measured characteristics by Ward method 
The progeny of KVD2 and KVD4 open pollination were classified in the second group. The progeny of these populations were similar in values of seedling height and diameter, canopy width, annual growth increase and catalase activity, and showed the lowest leaf chlorophyll content.

KVD4 $\times$ 'Viduja' and KVD4 $\times$ KVD2 populations that had the same female parent were placed into separate groups. In the third group, population KVD4 $\times$ 'Viduja' was placed. The lowest length and diameter of shoots belonged to the progeny of this population. Population KVD4 $\times$ KVD2 was in the fourth group and had the lowest canopy width and highest catalase and peroxidase activity. It seems that the same female parents had not led to similarities between progeny in all populations.

At this moment, it is not possible to predict which of the analyzed at the vegetative stage traits can be markers for the future fruit yield. The observation will be carried out every year up to the stage of full yielding.

\section{REFERENCES}

Aebi H. 1984. Catalase in vitro. Methods in Enzymology 105: 121-126. DOI: $10.1016 / \mathrm{s} 0076-$ 6879(84)05016-3.

Abdollahi H., Ahmadi S. 2017. Susceptibility to chlorosis and its relationship to leaf iron contents in some genotypes of quince (Cydonia oblonga Mill.). Seed and Plant Improvement Journal 33(2): 133-151. DOI: 10.22092/spij.2017.115543. [in Persian]

Hiscox J.D., Israelstam G.F. 1979. A method for the extraction of chlorophyll from leaf tissue without maceration. Canadian Journal of Botany 57: 13321334. DOI: 10.1139/b79-163.

Marquard R.D., Tipton J.L. 1987. Relationship between extractable chlorophyll and an in situ method to estimate leaf greenness. HortScience 22: 1327-1333.
Mohammadi R., Maali-Amiri R., Mantri N.L. 2014. Effect of $\mathrm{TiO}_{2}$ nanoparticles on oxidative damage and antioxidant defense systems in chickpea seedlings during cold stress. Russian Journal of Plant Physiology 61: 768-775. DOI: 10.1134/s1021443714050124.

Petrokas R., Stanys V. 2008. Leaf peroxidase isozyme polymorphism of wild apple. Agronomy Research 6: 531-541.

Rajabpoor S., Kiani S., Sorkheh K., Tavakoli F. 2014. Changes induced by osmotic stress in the morphology, biochemistry, physiology, anatomy and stomatal parameters of almond species (Prunus L. spp.) grown in vitro. Journal of Forestry Research 25: 523-534. DOI: 10.1007/s11676-014-0491-9.

Rodríguez-Guisado I., Hernández F., Melgarejo P., Legua P., Martínez R., Martínez J.J. 2009. Chemical, morphological and organoleptical characterisation of five Spanish quince tree clones (Cydonia oblonga Miller). Scientia Horticulturae 122: 491-496. DOI: 10.1016/j.scienta.2009.06.004.

Sahin O., Gunes A., Taskin M.B., Inal A. 2017. Investigation of responses of some apple (Mallus $\times$ domestica Borkh.) cultivars grafted on MM106 and M9 rootstocks to lime-induced chlorosis and oxidative stress. Scientia Horticulturae 219: 79-89. DOI: 10.1016/j.scienta.2017.03.006.

Samar S.M., Samavati S., Tadayon M.S., Rezai H., Tehrani M.M., Ardakani M.S. et al. 2010. Iron in Soil and Plant. Iranian Soil and Water Research Institute, Karaj, Iran. 191 pp. [in Persian]

Sun B., Jing Y., Chen K., Song L., Chen F., Zhang L. 2007. Protective effect of nitric oxide on iron deficiency-induced oxidative stress in maize (Zea mays). Journal of Plant Physiology 164: 536-543. DOI: 10.1016/j.jplph.2006.02.011.

Tatari M., Abdollahi H., Mousavi A. 2018. Effect of pollination on dropping of flowers and fruits in new quince (Cydonia oblonga Mill.) cultivar and promising genotypes. Scientia Horticulturae 231: 126 132. DOI: 10.1016/j.scienta.2017.10.045. 
Wu Y., Taylor K.E., Biswas N., Bewtra J.K. 1999. Kinetic model for removal of phenol by horseradish peroxidase with PEG. Journal of Environmental Engineering 125: 451-458. DOI: 10.1061/(asce)0733-9372(1999)125:5(451).

Walinga I., Van Vark W., Houba V.J.G., Van der Lee J.J. 1989. Soil and Plant Analysis. Part 7. Plant
Analysis Procedures. Wageningen Agriculture University, the Netherlands.

Zhang X.Z. 1992. The measurement and mechanism of lipid peroxidation and SOD, POD and CAT activities in biological system. In: Zhang X.Z. (Ed.), Research methodology of crop physiology. Agriculture Press, Beijing, pp. 208-211. [in Chinese] 